\title{
Reviving degraded monuments of fortification architecture - a potential for the development of small historical towns
}

\author{
Nellya Leshchenko ${ }^{1}$, Valerii Tovbych ${ }^{2}$ \\ ${ }^{1}$ Department of Information Technologies in Architecture; \\ Kyiv National University of Construction and Architecture; \\ Kyiv 03037, Povitroflotskyi prospect 31, Ukraine; \\ ardisconn@ukr.net (iD)0000-0002-3198-4554 \\ ${ }^{2}$ Department of Information Technologies in Architecture; \\ Kyiv National University of Construction and Architecture; \\ Kyiv 03037, Povitroflotskyi prospect 31, Ukraine; \\ (iD) 0000-0002-4794-4944
}

\begin{abstract}
This article proposes a strategy for the revival of degraded monuments of fortification architecture as a source of the future small historical towns development in general and the improvement of their inhabitants life quality. The recommendations on how to adapt them to cultural and tourist clusters are discussed in detail in the project of Klevan Castle revival.

Keywords: revival; degraded monuments of fortification architecture; castle; cultural and tourist cluster

\section{Introduction}

Small historical towns have a tremendous historical value to the cultural heritage, they contain numerous architectural and urban planning monuments of national and local importance. However, in most cases, they have been neglected over the years and are currently in a state of delapidation. This is caused by their misuse or non-use at all. Further ignorance of this problem may lead to their complete destruction; a loss of authentic buildings and urban planning dominants.

Among the most neglected are the monuments of fortification architecture, which have a certain interesting feature. Despite their state of preservation, the «spirit of the place» feels very strongly about them and therefore they always inspired interest in themselves. They also form the historical, cultural, and architectural (as its material component) potential of almost every historical small town. Moreover, they can become an incentive and a source of the town's future development as a cultural and tourist centre.
\end{abstract}


This brings the following questions: How to revive abandoned and degraded architectural monuments and, above all, castles and fortresses, which are now unused and and in the constant process of decay? Will their conservation and museification be sufficient to activate and involve them in modern urban life? What functions should be assigned to each town to preserve them physically and to enhance their historical, cultural, and socio-economic value? How, in general, should the historical potential of a small town be properly used for the prospect of its further development, attraction of tourists and investors, and improvement of the well-being of local residents? Although these issues remain relevant, they require detailed study.

\section{Purpose of the article}

To show the strategy of reviving abandoned monuments of fortification architecture (using the Klevan castle as an example) to transform them into centers for the preservation, promotion and development of urban culture and traditions, and sources for the future development of a small historical city as a whole.

The issues of preservation and modern use of monuments of fortification architecture are covered in great detail in research works of M. Bevz [1], M. Dyomin [2], M. Orlenko [3], L. Pribega [4], P. Rychkov [5], O. Rybchynskyi [6], P. Glen, K.Krupa [7] and others.

The existing documents for the preservation of the historical and cultural heritage are DBN B.3.2-1-2004 «Restoration, conservation and repair works on cultural heritage monuments» [8], and are presented in the «Collection of regulatory acts of the field of cultural heritage protection» [9].

\section{Basic material}

The analysis of the current state of development in small historical towns shows a rather difficult issue with the preservation and modern use of architectural monuments and historical buildings and, above all, monuments of fortification architecture. These monuments have sustained significant destructive changes over the years, which substantialy affected their value. There is a number of cases where the misuse or non-use leads to a complete destruction of the monument. Also, using them incorrectly can lead to unwanted changes, both in individual buildings as well as in historically established urban environment. The lack of funds leads to the fact that numerous monuments remain unremarkable and unfit for use, in decline and degradation. The inappropriate modern function, under which some of the monuments are adapted, constitutes yet another problem. This usually results in the loss of individual elements of the building, or in significant unwanted completion. Both lead to undesirable changes and loss of the architectural value of the monument.

Another issue is the poor quality of the existing urban environment, that does not facilitate its activity. Absence or small number of places with optional urban functions related to culture, leisure and recreation. Absence of equipped and functionally filled places for long comfortable stay. In addition, there is a poorly developed tourist and service infrastructure. A person comes to the city to look at architectural monuments, and after a few hours he must leave it because of the lack of places to eat and stay. This causes low interest in visiting and investing in this town. And, as a result, it is losing potential finance for its development.

Therefore, in order to correct the situation outlined above, a comprehensive approach to carrying out restoration and reconstruction transformations should be taken, which would cover not only abandoned monuments, historical buildings, or spaces, but also the historical 
urban environment as a whole. At the same time, architectural and town-planning (planning, volume and spatial, architectural and figurative, functional) as well as ecological questions must be answered. Moreover, the social-economic component of the complete process of the town's degrading monuments integration into the modern city life and their influences on further development of the small historical town in general have to be solved.

The following strategy for solving the issues outlined above can be proposed:

- increasing the architectural value of monuments and surrounding territory with the promise of holistic restoration, recreation, revalorization, and regeneration to recover their architectural integrity;

- revival and attraction of the monuments into modern urban life by adapting them to modern and relevant functions, which will preserve their architectural image and will not disrupt volume planning and constructive systems;

- physical and functional filling of the open space which surrounds the monument and together with it forms a whole, with comfortable rest stops and places for a longer stay;

- setting it up for comfortable movement;

- filling the monument and surrounding space with interesting elements of art to increase the activity and socio-economic value.

These proposed strategies were put into the idea of a revival the castle in Klévan as the source for a further development of the entire small town and illustrated in the presented project.

Klevan (Rivne region) is a small historical settlement of the Volynsky region which was first described in a journal from 1458 [10]. Among the existing monuments of the national and local importance is the Prince's Chartoryiski Castle (1475) [11], which is the main urban planning dominant, and at the same time, is the most neglected.

Klavan Castle has a rich historical past. The construction of the castle was started in 1475 during the reign of Mikhail Vasilevich Chartoryiskyi [11]. The works were disrupted by legal disputes over the property of the Klevan lands between princes Chartoryiski and Radziwilly, owners of the neighboring Olyka. It was only in the middle of the 16th century when Radziwilly renounced their claims to the property rights in favor of Prince Ivan Chartoryiskyi and his descendants. Therefore, the construction of the castle was finished in 1561 [5].

The castle had three towers (two stone, partially preserved until our time, and one wooden, which is now completey gone, and stone 2-storey and 3-storey buildings with basements [11]. At present the two-storey west, two-storey and three-storey northeast, and three-storey south buildings have been preserved. The castle was surrounded by man-made moats filled with the River Stubla's waters. A stone arch bridge, spilling over the moat from the north, was used to enter the castle. It has also been preserved to the present day (Fig. 1, 2). 

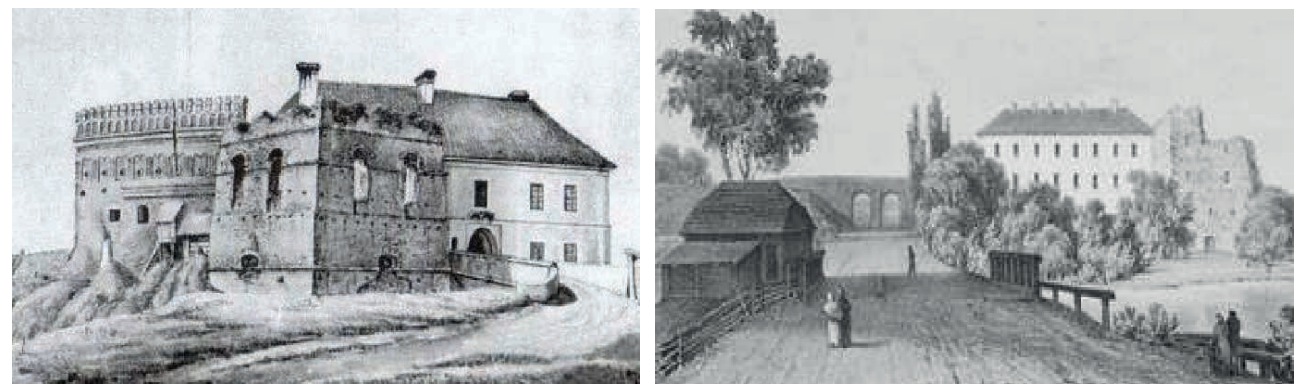

Fig. 1. Klevan Castle.Iconography [12, 13]

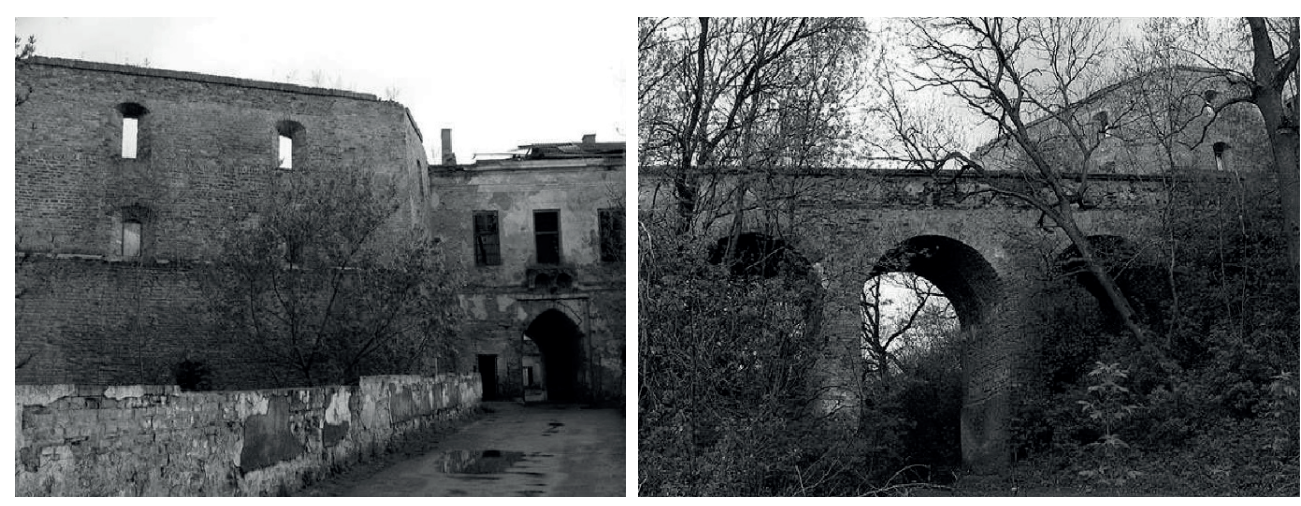

Fig. 2. Klevan Castle. Current status. View from the entry bridge. Photos by N. Leshchenko

The function of the castle had changed many times during its existence. After the loss of the original defensive function, almost for a century and a half, up to 1773 [14], it contained Jesuit missionaries, and it was used as a Jesuit board. The castle had a county school, gymnasium, military hospital, spiritual school, children's colony, and boarding school. Its final function was medical and labour prevention. This use devalued its historical, cultural, and architectural value, however it somehow allowed to maintain physical existence and prevented its total destruction.

The castle has not been used since the late 20th century. Just like 200 years ago, during the first long period of the abandonment, it went into a coplete decay (Fig. 3, 4).
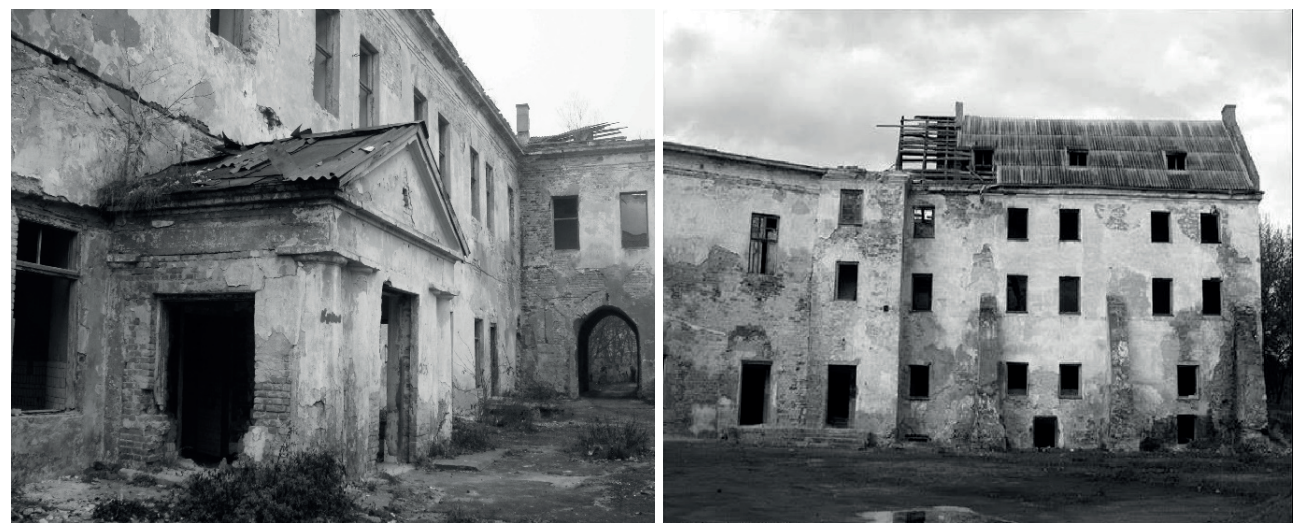

Fig. 3. Klevan Castle. Current status. View from the courtyard. Photos by N. Leshchenko 


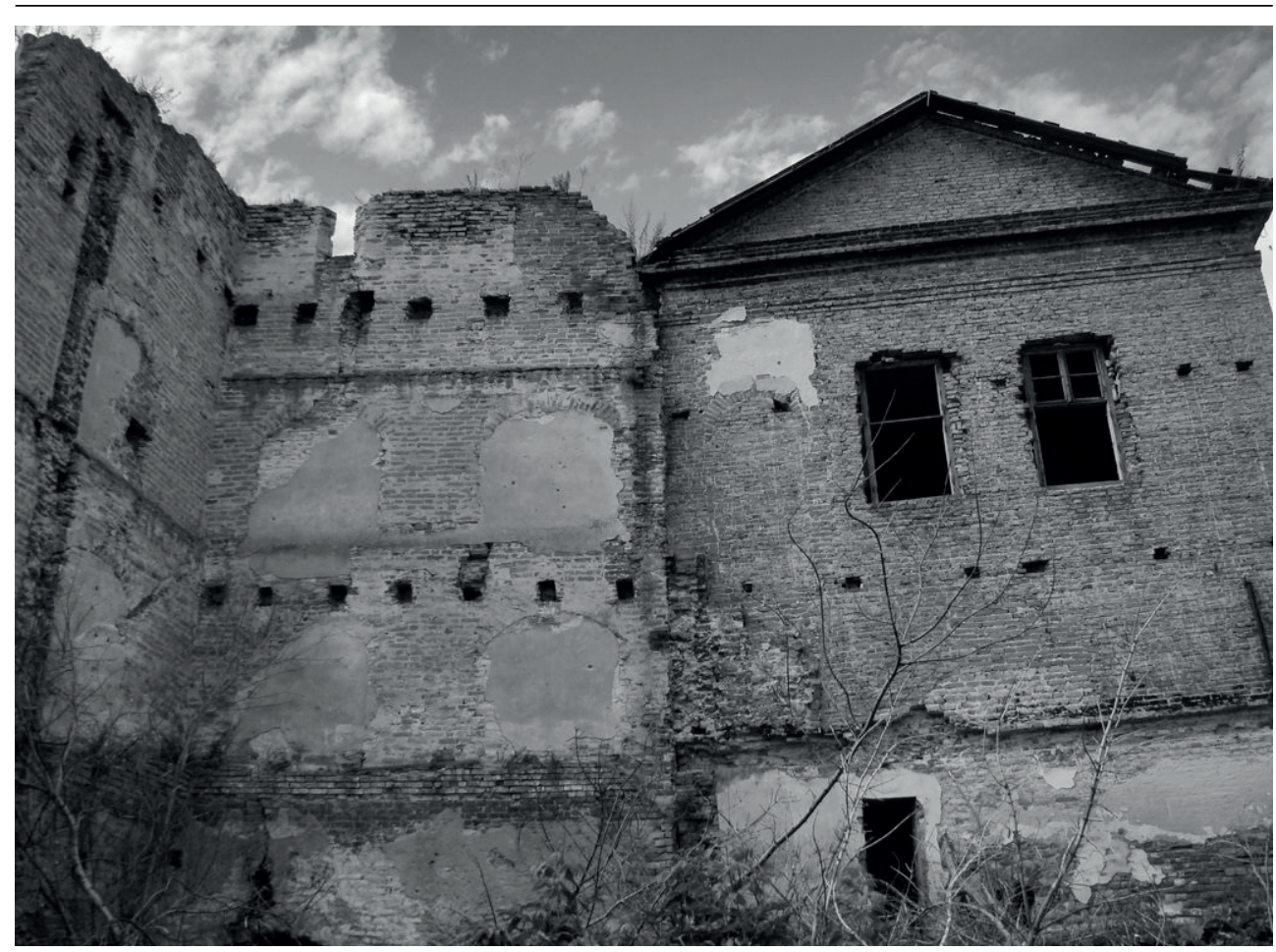

Fig. 4. Klevan Castle.Current status. View of the inside of the west tower. Photos by N. Leshchenko

Two options for returning the degraded architectural monument to active physical and social life were considered. The first proposed transformation is the introduction of the process of conservation and museification. In this case, the destroyed castle would become a museum exhibit and the area around it would be merged into the city park. This will increase its historical and social value by giving the castle a new function and transforming it into the city's green recreational area. However, the preservation of the monument in its existing form and its museification alone will not increase its architectural value. Therefore, first of all, a more active and modern use of the object should be proposed. It will provide a functional content and diversity with would interest different parts of the society, and thus ensure the renewal of its socio-economic value. Secondly, abandoned parts of the degraded castle would be restored and recreated to enhance its architectural value.

Thus, it has been proposed to use a combination of certain restoration and reconstructive transformation methods that will enhance each other 's action and together lead to the revival of the abandoned architectural monument. They are: revalorization - in order to increase the historical, cultural, architectural and socio-economic value of the castle building itself and the surrounding territory; combined with holistic restoration - to restore the existing part of the castle; regeneration - to return architectural and compositional integrity; with recreation of its lost parts and adaptation to new topical functions with preservation of the historical volume-planning and structural system, to attract the modern urban life.

The authenticity of the monument should be preserved as much as possible. It was proposed to allocate a part of the castle, renewed by existing iconography, so that its authentic part [15] could be determined immediately. It is proposed to separate it with some finishing 
material, such as smooth plaster (as in iconography), with elements of masonry, which would stand out from the restorated south part of the castle with a glass transition-insert (Fig. 5).

The proposed functional adaptation involves adapting the castle as a whole as the museum and tourist cluster. The castle is to become an urban, cultural, and recreational centre with an active, day-to-day, permanent or periodic, long, and short-term performance.

It will be advisable to hold permanent, and mobile exhibitions, master classes for training programmes, display and distribution of traditional crafts, art festivals, ethno festivities, city holidays, to organize knight tournaments [15], to create reconstruction of historical events related to the town and castle on its territory. For this purpose, restorated and recreated parts of the castle building and its territory should be arranged for comfortable, long stay, and should be filled with various functions, which complementing and reinforcing each other, would activate and contribute to its transformation into a cultural and tourist cluster.

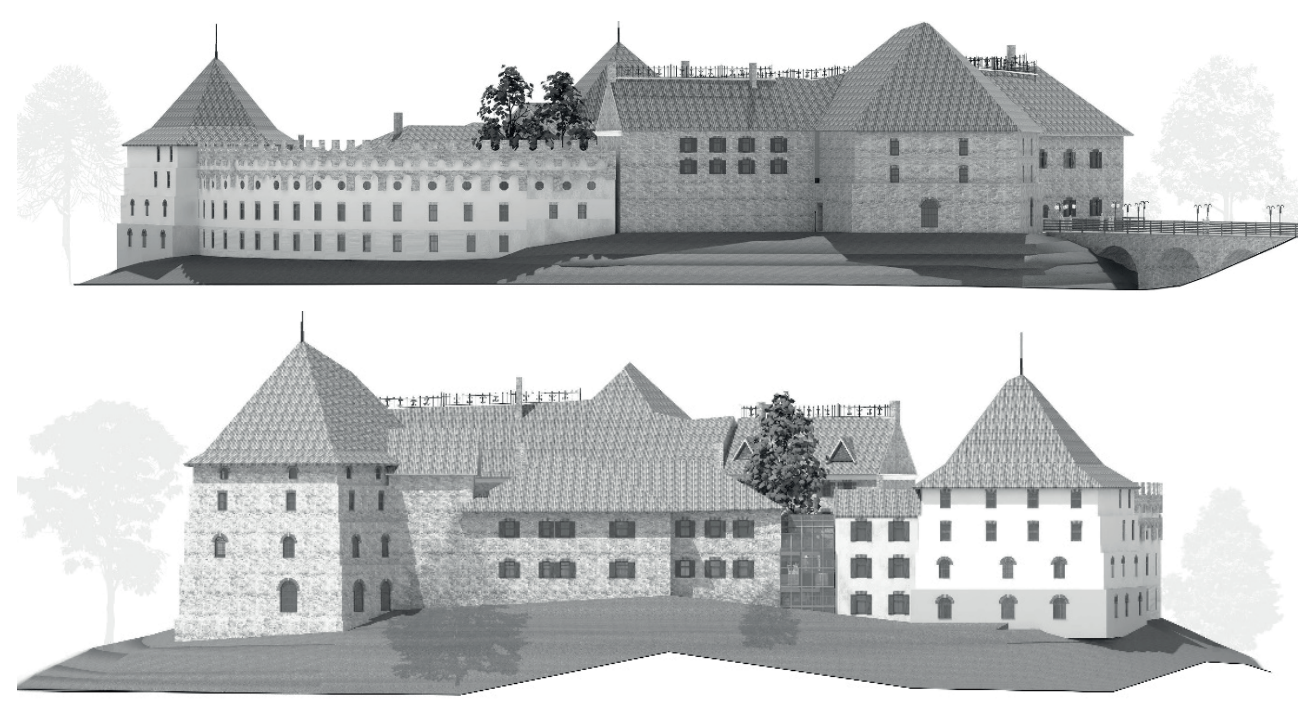

Fig. 5. The project proposal of Klevan Castle revival. East and South views.. Completed: A. Yakovleva, student ITA KNUCA; head: N. Leshchenko, Ph.D arch., associate professor ITA KNUCA

The north-east tower is proposed to be adapted into a tourist and information centre with a gift shop, a lounge, and a lecture theathre. This function will be easy to enter based on the store existing planing and the structural system - the tower is divided into four floors by a flat slab.

In the west and north-east buildings it is proposed to place exhibition halls, rooms for master classes, as well as administrative premises. This is facilitated by the preservation of the existing planning with one-side placement of the premises and the availability of natural light in them. 


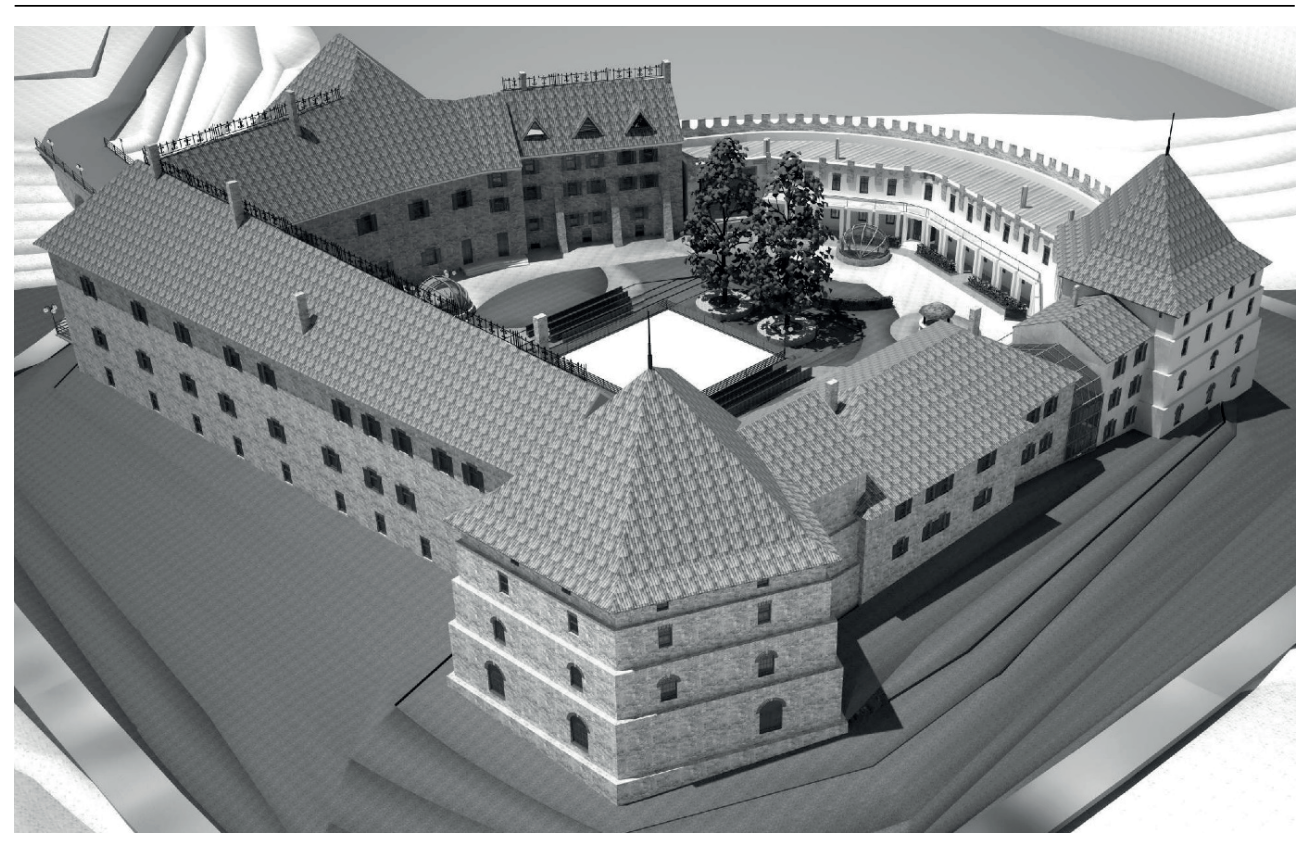

Fig. 6. The project proposal of Klevan Castle revival.General view. Completed: A. Yakovleva, student ITA KNUCA; head: N. Leshchenko, Ph.D arch., associate professor ITA KNUCA

After recreation in the western tower it is proposed to organize a restaurant serving the Ukrainian national cuisine. The restored south building and recreated eastern and southeastern part of the castle are proposed to become a mini-hotel with facilities for conferences, seminars, and a small cinema. On the roof of the eastern building it is proposed to place an observatory. In this part of the castle technical rooms also would be located, These facilities would serve the whole complex.

The courtyard is proposed to become a multifunctional space, interesting to visit, comfortable for the stay and movement. It would combine the recreational, communicative, service, educational, cultural, and art functions. It is proposed that the spot where active periodic, long-term, or short-term event performances would take place. For this purpose it is proposed to create a scene arena for different performances and presentations, open areas for thematic exhibitions, and master classes. The courtyard would become a place for more peaceful, permanent performances in conjunction with a long, comfortable stay premisses, observation platform, open areas for cafes, as well as grass-coated rest areas developed with the use of geoplasty techniques Geoplasty techniques.

In general, the courtyard and castle as a whole should be transformed into a place, where one could tdip into the urban cultural life, get acquainted with local traditions, learn traditional crafts, relax, and socialise.

This would help not only to make the degraded monument and its surrounding territory relevant and interesting, but also contribute to the development of the event tourism, and attract funds to the town for its further development and improvement of the quality of local residents' life. The aim is that the castle becomes the centre of the revival of the small town. 


\section{Conclusions}

In the nutshell, the revival of degraded and abandoned monuments of fortification architecture is a complex process which which pays off with the increase in their value and the quality of their urban environment. It should include various methods of restoration and reconstructive transformations, which complement and strengthen each other's action and help their preservation and transition into a new qualitative level. The purpose of these transformations is not limited to restoring and reviving specific monuments, it is equivocally aimed at improving of the quality of the entire historical urban environment, attracting attention of tourists and investors, and thus developing a small historical town as a whole. and last, but not least, improving the quality of life of its inhabitants.

\section{References}

[1] Bevz M., "Noties to the history and hypothetic reconstruction of the architectural-planning structure of the castle of Rohatyn", Current issues in research, conservation and restoration of historic fortifications, no. 10, (2018), pp. $17-29$.

[2] Dyomin M., Ivashko O., "System approach to historical fortifics revaluation and industrial territories after art clusters", Current issues in research, conservation and restoration of historic fortifications, no. $10,(2018)$, pp. $30-33$.

[3] Orlenko M., "Methodical approaches to architectural conservation", Current issues in research, conservation and restoration of historic fortifications, no. 9, (2017), pp. 209 -213.

[4] Prybyega L., Protection and restoration of the architectural and urban heritage of Ukraine, Kyiv, 2009.

[5] Rychkov P., Roads of southern Rivne region. Moscow, 1989.

[6] Rybchynskyi O., Khokhon M., "The Western Ukraine downtown monastery complexes of 17-18 th centuries: the principles of the defenses formation", Current issues in research, conservation and restoration of historic fortifications, no. 9, (2017), pp. $240-247$.

[7] Glen P., Krupa K., "Klodzko fortress - possibility of adaptation", Current issues in research, conservation and restoration of historic fortifications, no. 9, (2017), pp. 257 -265.

[8] DBN B.3.2-1-2004: Restoration, conservation and repair works on monuments of cultural heritage, Kyiv: Ministry of Regional Development of Ukraine, 2005.

[9] Serdyuk O.M., Collection of normative legal acts of the sphere of protection of cultural heritage. Chernigiv, 2011.

[10] Vodzinsky E.E., Methodical recommendations for the study of the historical and architectural heritage in the cities of the Ukrainian SSR, Kyiv, 1982.

[11] Monuments of urban planning and architecture of the Ukrainian SSR. Kyiv, 1985.

[12] Castles of Ukraine. Available: https://it.foursquare.com/o_yakymchuk/list/замки-україни. [Access: 29 Oct 2019].

[13] Castles and temples of Ukraine. Available: https://castles.com.ua/klevan.html. [Access: 29 Oct 2019].

[14] Teodorovich NI, Historical and Statistical Description of the Churches and Parishes of the Volyn Diocese: Counties of Rivne, Ostrozhsky and Dubensky, Pochaev, 1889.

[15] Leshchenko N., "Revalorization of iconic urban complexes of historical centers of small towns (on example of Klevan, Rivne region)", Current issues in research, conservation and restoration of historic fortifications, no. 9 (2017), pp. $146-151$. 